\title{
Effects of gamma radiation on adipose-derived mesenchymal stem cells of human breast tissue
}

\section{S. Taeb1, M.A. Mosleh-Shirazi'1,2, A. Ghaderi3,4, S.M.J. Mortazavi5 ${ }^{*}$, M. Razmkhah ${ }^{*}$}

\author{
${ }^{1}$ Ionizing and Non-ionizing Radiation Protection Research Center (INIRPRC), School of Paramedical Sciences, \\ Shiraz University of Medical Sciences, Shiraz, Iran \\ ${ }^{2}$ Department of Radio-oncology, Shiraz University of Medical Sciences, Shiraz, Iran \\ ${ }^{3}$ Shiraz Institute for Cancer Research, School of Medicine, Shiraz University of Medical Sciences, Shiraz, Iran \\ ${ }^{4}$ Department of Immunology, School of Medicine, Shiraz University of Medical Sciences, Shiraz, Iran \\ ${ }^{5}$ Department of Medical Physics and Engineering, Shiraz University of Medical Science, Shiraz, Iran
}

\section{- Original article}

\author{
*Corresponding authors: \\ Mahboobeh Razmkhah, PhD., \\ E-mail: \\ razmkhahm@sums.ac.ir \\ S.M.J. Mortazavi, PhD., \\ E-mail: \\ mmortazavi@sums.ac.ir \\ Revised: December 2019 \\ Accepted: January 2020 \\ Int. J. Radiat. Res., January 2021; \\ 19(1): 175-182 \\ DOI: $10.29252 /$ ijrr.19.1.175
}

\section{ABSTRACT}

Background: During radiation therapy, stromal cells surrounding the tumor (e.g mesenchymal stem cells) may affect the treatment outcomes. We aimed to investigate the effects of gamma radiation on the mRNA expression of cytokines, DNA damage and population doubling time (PDT) of adiposederived mesenchymal stem cells (ASCs). Material and methods: ASCs were enzymatically extracted from breast tissue and exposed to different doses of 5,10 , and $30 \mathrm{~Gy}$ of gamma radiation. The capability of ASC proliferation, the level of DNA damage, and the expression of angiogenic and immunosuppressive factors were evaluated using PDT, comet assay, and qRT-PCR, respectively. Results: Gamma irradiation of ASCs with different doses of 5, 10, and 30 Gy significantly increased PDT and DNA damage in a dose-dependent manner $(P<0.05)$. A dose of 5 Gy caused a significant increase in SDF-1 whereas a 10 Gy dose significantly increased the expression of both SDF-1 and IL-10 ( $P<0.05)$ in ASCs. Conclusion: Results indicate that different doses of gamma irradiation may induce angiogenesis and immunosuppression in ASCs via different cytokines which may affect the radiotherapy outcome.

Keywords: Radiation, stem cell, tumor microenvironment, angiogenesis, immunosuppression.

\section{INTRODUCTION}

Radiotherapy, which includes 4 to 5 weeks of daily radiation treatment courses, is a standard method for thetreatment of most breast cancer patients (1). Despite the significant role of radiotherapy in cancer treatment, some side-effects associated with breast cancer irradiation have been reported $(2,3)$. The first response to irradiation in the tumor micro environment is inflammation caused by oxidative stress affecting stem cells in the tumor microenvironment which are very sensitive to radiation $(4,5)$. Studies have shown that cancer cells are capable of interacting with their surrounding stroma (6). Mesenchymal stem cell (MSC) recruited to the tumor microenvironment causes tumor progression and metastasis of tumor cells due to their immunomodulatory and angiogenic properties $(7,8)$. Indeed, MSCs are pluripotent and progenitor cells with the capability of unlimited division and differentiation to various cell types(9). MSCs induce angiogenesis through the release of proangiogenic factors such as VEGF (10). However, exposing MSCs to distinct doses of irradiation led to the emergence of antiangiogenic properties but did not change the 
immunomodulatory features of these cells $(11,12)$. Irradiated adipose-derived mesenchymal stem showed decreased proliferation and senescence, however, they maintained their osteogenic but not adipogenic and chondrogenic differentiation ability (13). ASCs from breast tissue were assigned with an intermediate radiation sensitivity and high repair capacity of DNA through increased expression of cyclin-dependent kinase (CDK) inhibitor p21 (14).

On the other hand, the role of stem cells in tumor cell development and possible modification of radiation treatment has been reported $(15,16)$. Due to the presence of MSCs in the vicinity of tumor cells and their important role in modulation of the tumor environment, the impacts they receive from different doses of radiation may affect their relationship with the tumor cells and the fate of the tumor. Accordingly, we aimed to investigate the effect of gamma radiation on the mRNA expression of angiogenic and immunosuppressive factors, DNA damages and on population doubling time of ASCs from breast tissue. The results may provide new insights into the design of cancer treatment.

\section{MATERIALS AND METHODS}

\section{Sampling of adipose tissue}

The present study was approved by the ethics committee of Shiraz University of Medical Sciences (Ethics Committee Code No.IR.SUMS.REC.1396.S.290). The samples were randomly collected from the women referred to the MRI and Frahmand far Hospitals for mammoplasty surgical services of hospitals in Shiraz, Iran. All donors provided written and signed informed consent to have the possibility of testing on their samples. Medical information of all participants will be kept private. Participants with a history of chemotherapy, radiotherapy, and medical conditions (e.g. autoimmunity) were not included in this study.

\section{ASCs: isolation and culture}

Mesenchymal stem cells (MSCs) were isolated from normal adipose tissue of the breast. In this

\section{6}

study, all participants were healthy women whose mean age \pm SD was $38 \pm 4$ years. All donors were selected randomly and adipose tissue of breast was isolated during mammoplasty surgery and straightway transported to the Cancer and Stem Cell Laboratory, Institute for Cancer Research, SUMS and further processed for isolation of mesenchymal stem cells based on established protocol (17). In brief, the breast adipose tissue was washed twice with Phosphate Buffered Saline (PBS). Then, it was processed by briefly mincing and incubating with collagenase type 1 enzyme (Gibco, USA) in Hank's balanced salt solution buffer (Gibco, USA) at $37^{\circ} \mathrm{C}$ for 40 minutes. Afterward, the cell suspension was centrifuged at $1000 \mathrm{~g}$ for $5 \mathrm{~min}$ and the resulted cell pellet was cultured in DMEM medium supplemented with $1 \%$ penicillin/streptomycin and $10 \%$ fetal bovine serum (FBS, Gibco, USA). The cell culture medium was changed every three days and the third passage of the cells was used for the experiments. Before any experiment, ASCs were characterized for the expression of MSC specific markers (positive for CD44, CD105 and CD166 and negative for CD14, CD34 and CD45) using flow cytometry method (FACS Calibur, BD biosciences, USA). Briefly, ASCs were harvested using dissociation solution (Sigma, USA). Then, $5 \times 10^{6}$ ASCs were washed twice with PBS and stained with phycoerythrin (PE)-conjugated mouse anti-human CD44, CD105 and CD166 (BD Biosciences, USA) and fluorescein isothiocyanate (FITC)-conjugated mouse anti-human CD14, CD34 and CD45 (BD Biosciences, USA). Corresponding isotype antibodies were used as negative controls (BD Bioscience, USA).

\section{Irradiation geometry}

When the confluency of ASCs reached $80-90 \%$, they were exposed to radiation with doses of 5, 10 or 30Gy of gamma radiation (dose rate of $0.28 \mathrm{~Gy} / \mathrm{min}$ ) (12). Our control group was ASCs which was kept in the same condition without exposing to gamma irradiation. Dosimetry was performed with an ionization chamber (Dosemeter PTW Unidos 1001/PTW TM 313, RPD Inc) in the Radiotherapy and

Int. J. Radiat. Res., Vol. 19 No. 1, January 2021 
Radiation Oncology Department of Namazi Hospital, SUMS. ASCs were irradiated with gamma rays emitted from a Theratron cobalt-60 therapy unit (MDS Nordion, Canada). We tried to have enough build-up and uniform irradiation of gamma rays on the cells. For this purpose, the exposure time was calculated for a distance of $80 \mathrm{~cm}$ and $35 \times 35 \mathrm{~cm}^{2}$ field of view and a depth of $4 \mathrm{~cm}$.

\section{Comet assay}

In this study, neutral comet assay was used for the detection of DNA double-strand breaks in ASCs after exposure to 5, 10 and 30Gy of gamma radiation. To fix the possible DNA breaks following irradiation, the samples were placed in an icebox and straightway returned to the incubator. The comet assay was performed as described by Wang et al. but with a slight modification (18). Briefly, irradiated cells were washed with PBS and centrifuged at $300 \mathrm{~g}$ for 5 minutes. The supernatant was removed and the remaining cell suspension was combined with \%1 low melting agarose (Type VIIA; Sigma-Aldrich, Poole, UK) at a concentration of $1 \times 10^{6}$ cells $/ \mathrm{ml}$. Afterward, $100 \mu \mathrm{l}$ of this suspension was loaded onto microscope slides coated by high-melting agarose (Sigma-Aldrich, Poole, UK) to form a microgel. To achieve reliable results, we prepared two slides for each sample. The comet slides were immersed in cold fresh lysis solution, $2.5 \mathrm{M} \mathrm{NaCl}, 1 \% \mathrm{~N}$-sodium lauryl sarcosinate, $30 \mathrm{mM}$ Na2EDTA, $10 \mathrm{mM}$ Tris, 1\% Triton X-100, 10\% DMSO, for 1.5 hours at $4{ }^{\circ} \mathrm{C}$. After lysis, they were located in buffer for 20 minutes in a horizontal electrophoresis tank filled with cold fresh Tris-borate-EDTA buffer to release the tight double-helical structure of DNA for electrophoresis. Electrophoresis was performed for 30 minutes at room temperature (25 V, $300 \mathrm{~mA}$ ) and the samples were neutralized with a neutralization solution for 5 minutes and fixed in ice-cold methanol. Finally, DNA was stained with propidium iodide $(20 \mu \mathrm{g} /$ $\mathrm{ml}$ ) and imaged with an Atomic Force Microscope (Nano wizardly-JPK, Germany). The comet tail regions of ASCs were measured using Comet Score software (about 50 cells in each slide).

Int. J. Radiat. Res., Vol. 19 No. 1, January 2021

\section{Population Doubling Time (PDT)}

In order to compare the growth rate of ASCs following exposure to gamma radiation emitted from the Co-60 source, the PDT was measured in the third passage ASCs irradiated with either 0 , 5,10 or 30 Gy and then were harvested and $5 \times 10^{3}$ cells were seeded in 96 multi-well plates. The cells were incubated again and counted 24, 48, 72 and 168 hours after irradiation by trypan blue staining. The experiment was repeated five times for each cell in each condition. Finally, the doubling time of ASCs was calculated using online doubling time calculator (http:// www.doubling-time.com/compute.php).

\section{RNA isolation and cDNA synthesis}

Seventy two hours after gamma radiation ASCs cell culture supernatant was removed and the adhered ASCs were washed twice with PBS. Next, total RNA was extracted using $1 \mathrm{ml}$ of cold RNX-Plus (Cinnagene, Iran). To check the accuracy of the RNA samples, optical densities of isolated RNA were read at 260 and $280 \mathrm{~nm}$ using a NanoDrop spectrophotometer (Wilmington, DE, USA). In the next step, cDNA was produced from the extracted RNAs using the cDNA synthesis kit following the manufacturer's instruction (Fermentas, Canada).

\section{Quantitative real-time PCR ( $q R T$-PCR)}

To assess the effect of gamma radiation on angiogenic factors of vascular endothelial growth factor (VEGF), stromal cell-derived factor-1 (SDF-1), immunosuppressive factors of human leukocyte antigen-G5 (HLA-G5), and interleukin 10 (IL-10) in ASCs, the qRT-PCR method was used. All qPCR reactions were measured at least two times using 2XSYBR Green Master Mix (Applied Biosystems, USA) based on the hot-start Jumpstart Taq DNA Polymerase enzyme (Sigma, USA). The amplification was done for 40 cycles $\left(95^{\circ} \mathrm{C} 20\right.$ sec, $60{ }^{\circ} \mathrm{C} 20 \mathrm{sec}, 72{ }^{\circ} \mathrm{C} 40 \mathrm{sec}$ ) and the qRT-PCR amplification products were verified by melting curve analysis. The $\beta$-actin gene was used as the housekeeping gene. To verify reaction efficiencies for each primer set, standard curves were prepared using data from serially diluted samples. Melting curve analyses were also 
performed for each primer set. Prior to data analysis, the melting curve for each gene was examined, and by examining this curve, the specificity of the target gene and the lack of a primer dimer was verified. Each experiment was conducted twice independently, with each sample measured in duplicate. Finally, considering the expression of control samples ( $\beta$-actin), the $\Delta \Delta \mathrm{Ct}$ method was used to determine the fold change of mRNA compared to the control group. Table 1 shows the forward and reverses primers for $\beta$-actin, VEGF, SDF-1, IL-10, and HLA-G5.All the primers used in this study were designed by AllelID software (Oligo Perfect Designer, Invitrogen, USA).

\section{Statistical analysis}

Data were analyzed by SPSS software version

Table 1. Forward and reverse primers of $\beta$-actin, SDF-1, VEGF, IL-10 and HLA-G5 genes for real-time PCR amplification.

\begin{tabular}{|c|c|c|}
\hline \multicolumn{1}{|c|}{ Primers } & Sequence & $\begin{array}{c}\text { Product } \\
\text { length }\end{array}$ \\
\hline$\beta$-actin forward & ACAGAGCCTCGCCTTTGCCG & 190 \\
\hline$\beta$-actin reverse & CACCATCACGCCCTGGTGCC & 190 \\
\hline SDF-1 forward & TGCCAGAGCCAACGTCAAG & 73 \\
\hline SDF-1 reverse & CAGTTGGGCTACAATCTGAA & 73 \\
\hline VEGF forward & CCCACTGAGGAGTCCAACAT & 186 \\
\hline VEGF reverse & TTTCTTGCGCTTTCGTTTTT & 186 \\
\hline IL-10 forward & TGGTGAAACCCCGTCTCTAC & 96 \\
\hline IL-10 reverse & CTGGAGTACAGGGGCAGTAT & 96 \\
\hline HLA-G5 forward & CTGGTTGTCCTTGCAGCTGTAG & 80 \\
\hline HLA-G5 reverse & CCTTTTCAATCTGAGCTCTTCTTT & 80 \\
\hline
\end{tabular}

21. For the normal distribution of data, parametric tests and for the non-uniform distribution of data, nonparametric statistical methods (Mann-Whitney and Wilcoxon) were used. $\mathrm{P}<0.05$ was considered significant.

\section{RESULTS}

\section{Comet assay}

We used the comet assay to assess double-strand breaks of DNA in ASCs following various doses of 5,10 and 30Gy irradiation. Accordingly, we found that the percentage of DNA in the tail of the non-irradiated ASCs was $9.53 \pm 2.1 \%$. However, for ASCs receiving 5 Gy of gamma radiation, the percentage of DNA in the tail was $25.41 \pm 2.15 \%$, which was significant in comparison to the non-irradiated cells $(\mathrm{P}=0.003)$. Also, for ASCs receiving 10 and 30Gy of irradiation, the percentage of DNA in the tail was $31.66 \pm 1.48 \%$ and $61.47 \pm 4.84 \%$, respectively, which were significant in comparison to non-irradiated ASCs ( $\mathrm{P}=0.0002$ and $\mathrm{P}<0.0001$, respectively) (figure 1 ).

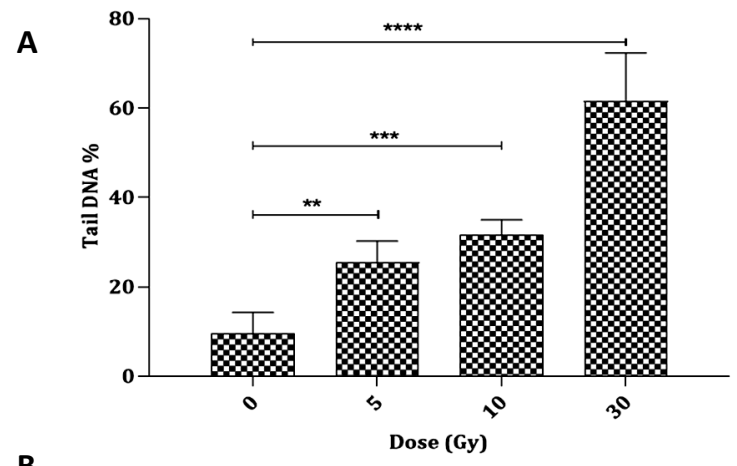

B
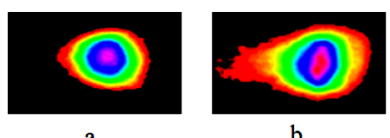

$\mathrm{b}$
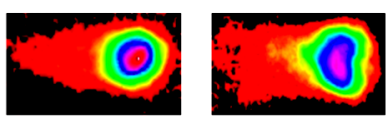

Figure 1. (A) The percentage of DNA in the tail of ASCs irradiated samples; the experiment was conducted twice for each sample. Error bars represent standard deviation of the mean and statistical significance was set at $\mathrm{P}<0.01\left({ }^{* *}\right)$, $\mathrm{P}<0.001\left({ }^{* *}\right)$ and $\mathrm{P}<0.0001(* * *)$. (B) DNA damage, detected with alkaline comet assay (refer to the Methods), after the exposure of ASCs to a) 0Gy, b) 5Gy, c) 10Gy and d) $30 \mathrm{~Gy}$ of gamma radiation.

\section{Effect of irradiation on PDT of ASCs}

First, the proliferation pattern of ASCs at passage three was evaluated at different time points of 24, 48, 72 and 168 hours and the mean \pm SD of the number of ASCs were $3220 \pm 319$,

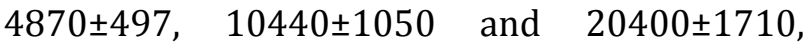
respectively (figure 2).

Evaluating the PDT showed that nonirradiated ASCs had the fastest doubling time recorded as $63.11 \pm 5.35$ hours. In irradiated ASCs, a relationship between the radiation intensity and increase in doubling time has been observed. The PDT of ASCs was 91.06 \pm 6.81 hours $(\mathrm{P}=0.022), 138 \pm 12.35$ hours $(\mathrm{P}<0.001)$ and $327 \pm 31.44$ hours $(\mathrm{P}<0.001)$ after exposing to 5 Gy irradiation, 10 Gy irradiation, and $30 \mathrm{~Gy}$ of gamma radiation, respectively (figure 3 ).

Int. J. Radiat. Res., Vol. 19 No. 1, January 2021 
Angi- A ogenic factors

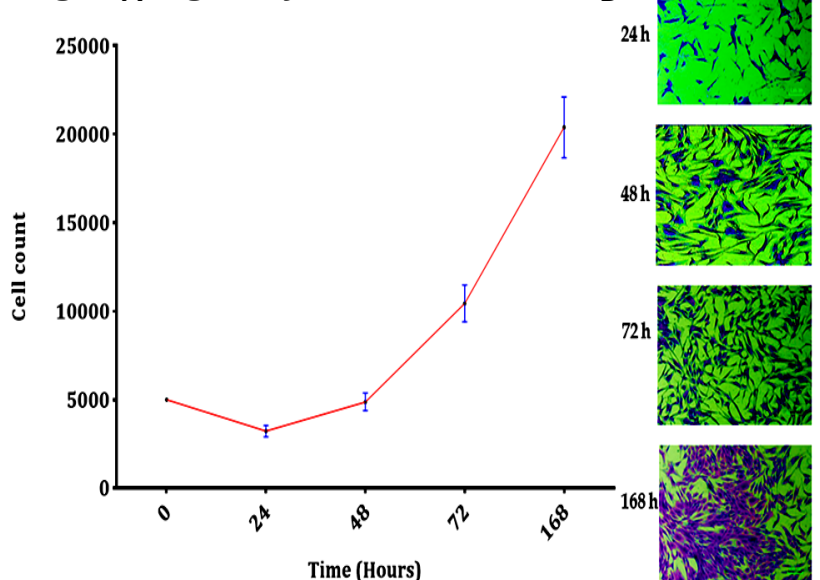

Figure 1. The growth curve (A) and the morphologic patterns (B) of ASCs. The cells were counted 24, 48, 72 and 168 hours by trypan blue staining. Error bars represent standard deviation of the mean.

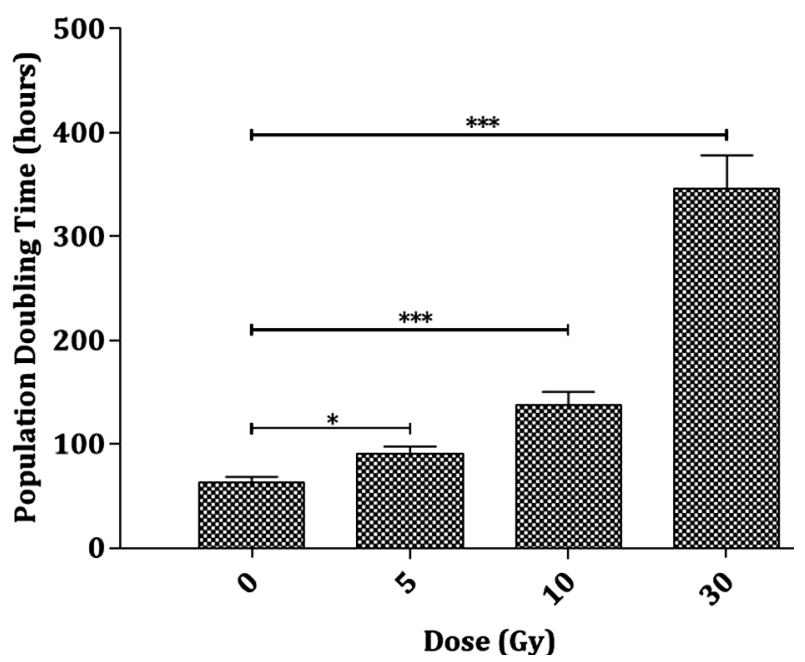

Figure3. The effect of irradiation on the Population Doubling Time of ASCs. Error bars represent standard deviation of the mean and statistical significance was set at $\mathrm{P}<0.05\left({ }^{*}\right)$ and $\mathrm{P}<0.001(* * *)$.

To understand the effect of gamma radiation on the angiogenic capability of ASCs, the expression of VEGF and SDF-1 was investigated, 72 hours after irradiation. As shown in figure $4 \mathrm{~A}$, irradiation to ASCs did not statistically change the expression of VEGF in doses of 5Gy, 10Gy, and 30Gy compared to non-irradiated ASCs $(\mathrm{P}>0.05)$. However, the irradiation seems to upregulate VEGF mRNA in all states.

Figure 4B shows that the irradiation increased the mRNA expression of SDF-1 in all groups. 5Gy and 10Gy gamma radiation significantly increased the expression of SDF-1 up to 6.84-fold ( $\mathrm{P}=0.007$ ), and 6.85-fold $(\mathrm{P}=0.006)$, respectively. This increase was not significant for 30Gy of irradiation $(\mathrm{P}=0.80)$.
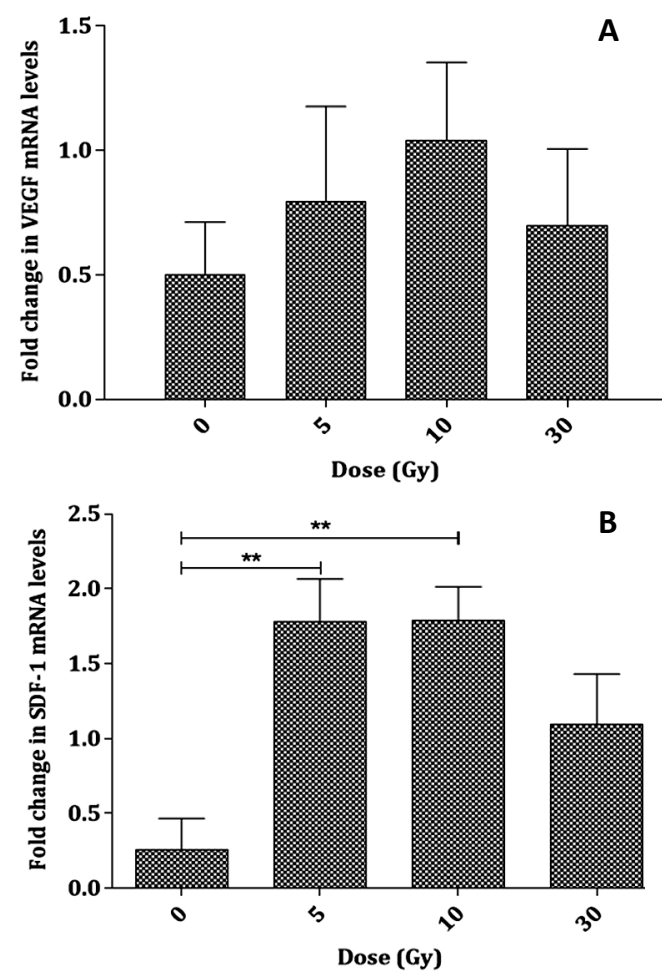

Figure 4. The fold change of mRNA level in A. VEGF and B. SDF-1 in ASCs exposed to 5, 10 and 30Gy irradiation compared to non-irradiated ASCs. Each experiment was conducted twice independently, with each sample measured in duplicate. Error bars indicate the standard deviation of the mean and statistical significance was set at $\mathrm{P}<0.01\left({ }^{* *}\right)$ regarding non-irradiated ASCs.

\section{munosuppressive factors}

In the next step, we examined the effects of 5, 10 and 30Gy of gamma radiation on IL-10 and HLA-G5 expression. According to figure $5 \mathrm{~A}$, the irradiation increased the mRNA expression of IL -10 in all groups, but the exposure of ASCs to $10 \mathrm{~Gy}$ of gamma radiation significantly increased the expression of $\mathrm{IL}-10$ 4.8-fold $(\mathrm{P}=0.002)$, regarding non-irradiated ASCs. This increase was not significant for 5Gy $(\mathrm{P}=0.08)$ and $30 \mathrm{~Gy}$ radiation $(\mathrm{P}=0.28)$.

As shown in figure $5 \mathrm{~B}$, irradiation to ASCs did not statistically change the expression of HLA-G5 after exposing to 5Gy, 10Gy and 30Gy 
compared to non-irradiated ASCs $(\mathrm{P}>0.05)$.
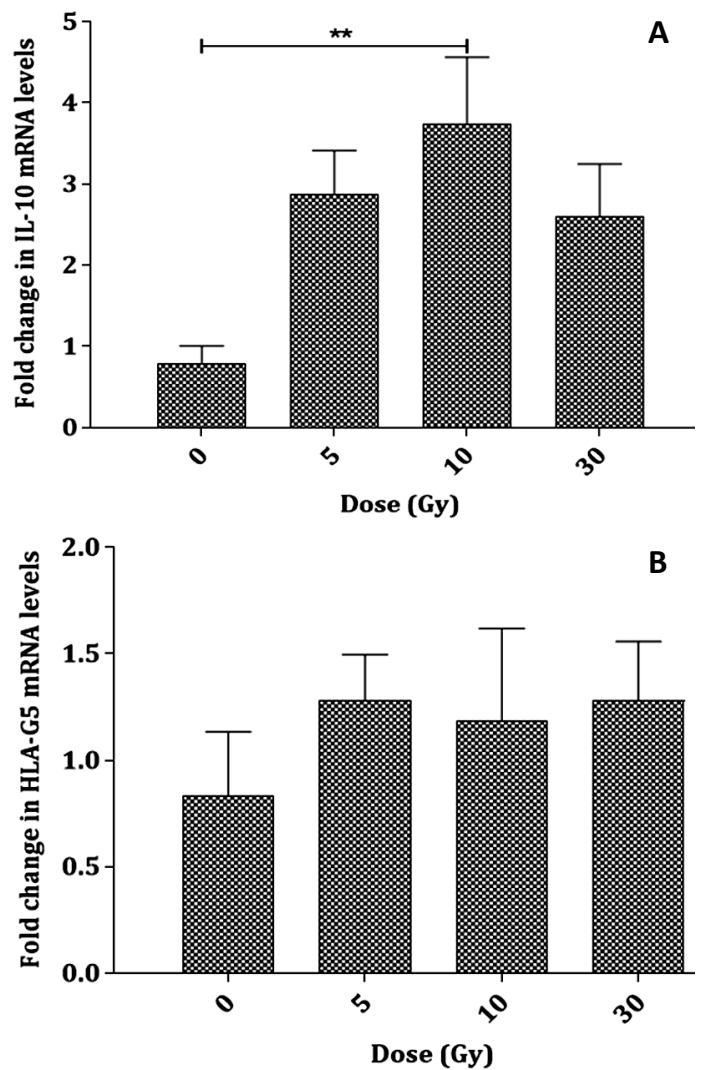

Figure 5. The fold change of mRNA level in A: IL-10 and B: HLA-G5 in the irradiated ASCs. Each experiment was conducted twice independently, with each sample measured in duplicate. Error bars indicate the standard deviation of the mean and the statistical significance was set at $\mathrm{P}<0.01(* *)$.

\section{DISCUSSION}

The present study was conducted to investigate the effect of gamma radiation on proliferation, DNA breaks, and expression of angiogenic and receive factors in ASCs from normal participants. Results showed that gamma radiation can increase DNA breaks and PDT in ASCs. Also, the irradiation of ASCs caused an increase in the expression of IL-10 and SDF-1.

We used the comet assay to investigate single -strand breaks in ASCs following exposure to various doses of gamma radiation. Venkatesh et al. reported that undifferentiated human embryonic stem cells have high sensitivity to ionizing radiation and the percentage of DNA breaks following gamma radiation in these cells was higher than the differentiated cells (19). In contrast, $\mathrm{Wu}$ et al. reported that MSCs have less radiosensitivity to gamma radiation in the early stages of growth, due to their stronger repair systems (20). Our results showed that by increasing the radiation doses from 5 to 30Gy, compared to the non-irradiated cells, the percentage of DNA breaks in ASCs increased. Since MSCs in the tumor microenvironment might positively effective in the growth and development of tumors, the possibility of controlling tumors by eliminating these cells using an appropriate dose of irradiation and inducing DNA breaks is not far away from the mind.

Also, we recorded the longest PDT in ASCs after 30Gy irradiation. Generally, our findings showed that when ASCs were exposed to 5, 10 and 30Gy of gamma radiation, PDT of the cells increased in a dose-dependent manner. In line with our results, Cmielova et al. reported a dose-dependent increase in PDT of bone marrow MSCs after gamma radiation, but no significant effect on cell viability following gamma radiation was observed. They showed that 20Gy irradiation reduces proliferation capacity in bone marrow MSCs (21). Also, some studies have revealed a correlation between prolonged PDT and a relative increase in radioresistance $(22,23)$. Accordingly, increased PDT in irradiated cells may provide more time to cope with irradiation-induced DNA damage. Hence, it seems that increasing the dose of irradiation is likely to increase DNA damage in the irradiated ASCs, activates repair mechanisms and finally increases PDT in irradiated cells.

Several investigations demonstrated that irradiation can increase the angiogenic capability of irradiated cells by up-regulating the expression of different cytokines, chemokines, and growth factors $(24,25)$. Our observation indicates that after exposure to 5 and 10Gy gamma radiation, SDF-1 was significantly upregulated in ASCs. In support of our work, Ponomaryov et al. reported an increased expression of SDF-1 in BM-derived osteoblasts after irradiation which can improve retention, homing, and repopulation of the cells damaged 
by irradiation (26). Moreover, Bastianutto et al. reported that $5 \mathrm{~Gy}$ of gamma radiation increased the expression of SDF-1 that leads to the recruitment of hematopoietic stem cells to the radiated bone marrow of mice (27). The irradiation reduces the vascularity leading to the expression of Hypoxic Inducible Factor-1 (HIF-1), activation of the SDF-1/CXCR4 pathway and finally repair the damage(28). Moreover, it has been shown that the expression of SDF-1 leads to an increase in the angiogenic ability of stem cells (29). Based on the present study, we concluded that the exposure to low doses of gamma radiation (5 and 10Gy in our study) are more effective than a high dose of irradiation on the production of SDF-1 in ASCs. Since expression of SDF-1 by MSCs may eventuate the tumor development, SDF-1 inhibitors following tumors irradiation may guide the improvement of clinical strategies to treat cancer cells and prevent the tumor recurrences after irradiation.

It has been demonstrated that after irradiation stem cells begin to secrete cytokines such as IL-10 for the repair of the damage through suppressing the immune system and preventing inflammation (30). In our study, we observed that irradiation of 10Gy to ASCs resulted in a significant increase in the expression of IL-10 in comparison to non-irradiated cells. Kang et al. reported that 9Gy irradiation increases the expression of IL-10 in hematopoietic stem cells of the mice; Suggesting that the secretion of IL-10 by hematopoietic stem cells may act as a contributory mechanism augmenting the self-renewal capacity of irradiated damaged cells (31). Thus, in comparison to our results, it seems that exposure to various doses of gamma radiation has different effects on the expression of IL-10 in different types of stem cells.

Based on the present study, with an increase in irradiation dose up to 10Gy, compensatory mechanisms (e.g. IL-10, and SDF-1) appear to be introduced to repair the damage while both may contribute to the development and growth of cancer. Obviously, assessment of two genes may not be enough to come to this conclusion and for better elucidation more studies on a broad range of molecules are undoubtedly required.
On the other hand, increasing the radiation dose to 30Gy augmented the DNA break and PDT while causing milder effects on the production of SDF-1 and IL-10. Therefore, during radiotherapy, the response of the stromal cells present in the tumor microenvironment may affect the treatment outcomes. Accordingly, it would be possible to obtain better results by choosing an optimal therapeutic dose of radiation affecting both tumor cells and stromal cells in the tumor microenvironment to treat tumors with radiotherapy.

\section{ACKNOWLEDGMENTS}

The authors would like to thank the patients and all the participants for their kind contribution to this project. This work was financially supported by Shiraz University of Medical Sciences, Shiraz, Iran (Grant no.12468) and Shiraz Institute for Cancer Research (ICR-100 -504). This research was extracted from Shahram Taeb's Ph.D. thesis for fulfilling his Ph. D. degree.

\section{Conflicts of interest: Declared none.}

\section{REFERENCES}

1. Potthoff K, Schmidt ME, Wiskemann J, Hof H, Klassen O, Habermann N, et al. (2013) Randomized controlled trial to evaluate the effects of progressive resistance training compared to progressive muscle relaxation in breast cancer patients undergoing adjuvant radiotherapy: the BEST study. BMC cancer, 13(1): 162.

2. Walker CM, Saldaña DA, Gladish GW, Dicks DL, Kicska G, Mitsumori LM, et al. (2013) Cardiac complications of oncologic therapy. Radiographics, 33(6): 1801-1815.

3. Daar E, Bradley D, Alkhorayef M, Al-Mugren K, Abdallat R, Al-Dousari H (2017) Towards evaluating post-irradiation tissue alterations. Radiation Physics and Chemistry, 137: 176-180.

4. Zhou D, Shao L, Spitz DR (2014) Reactive oxygen species in normal and tumor stem cells, in Advances in Cancer Research. Elsevier, p. 1-67.

5. Yamaguchi M and Kashiwakura I (2013) Role of reactive oxygen species in the radiation response of human hematopoietic stem/progenitor cells. PloS one, 8(7): e70503. 
6. Pietras K and Östman A (2010) Hallmarks of cancer: interactions with the tumor stroma. Experimental Cell Research, 316(8): 1324-1331.

7. Karnoub $A E$, Dash $A B$, Vo AP, Sullivan A, Brooks MW, Bell $\mathrm{GW}$, et al. (2007) Mesenchymal stem cells within tumour stroma promote breast cancer metastasis. Nature, 449 (7162): 557.

8. Shojaei S, Hashemi SM, Ghanbarian H, Salehi M, Mohammadi-Yeganeh S (2019) Effect of mesenchymal stem cellsderived exosomes on tumor microenvironment: Tumor progression versus tumor suppression.Journal of Cellular Physiology, 234(4): 3394-3409.

9. Liu ZJ, Zhuge Y, Velazquez OC (2009) Trafficking and differentiation of mesenchymal stem cells. Journal of Cellular Biochemistry, 106(6): 984-991.

10. Wu Y, Chen L, Scott PG, Tredget EE (2007) Mesenchymal stem cells enhance wound healing through differentiation and angiogenesis. Stem Cells, 25(10): 2648-2659.

11. Stefani, FR, Eberstål S, Vergani S, Kristiansen TA, Bengzon J (2018) Low-dose irradiated mesenchymal stromal cells break tumor defensive properties in-vivo. International Journal of Cancer, 143: 2200-2212.

12. de Andrade AVG, Riewaldt J, Wehner R, Schmitz M, Odendahl M, Bornhäuser M, et al. (2014) Gamma irradiation preserves immunosuppressive potential and inhibits clonogenic capacity of human bone marrow-derived mesenchymal stromal cells. Journal of Cellular and Molecular Medicine, 18(6): 1184-1193.

13. Jeong W, Yang X, Lee J, Ryoo Y, Kim J, Oh Y, et al. (2016) Serial changes in the proliferation and differentiation of adipose-derived stem cells after ionizing radiation. Stem Cell Research \& Therapy, 7(1): 117.

14. Baaße A, Machoy F, Juerß D, Baake J, Stang F, Reimer T, et al. (2018) Radiation Sensitivity of Adipose-Derived Stem Cells Isolated from Breast Tissue .International Journal of Molecular Sciences, 19(7): 1988.

15. Baaße A, Juerß D, Reape E, Manda K, Hildebrandt G (2018) Promoting effects of adipose-derived stem cells on breast cancer cells are reversed by radiation therapy. $C y$ totechnology, 70(2): 701-711.

16. Feng $\mathrm{H}$, Zhao Jk, Schiergens TS, Wang Px, Ou Bc, Al-Sayegh $\mathrm{R}$, et al. (2018) Bone marrow-derived mesenchymal stromal cells promote colorectal cancer cell death under lowdose irradiation. British Journal of Cancer, 118(3): 353.

17. Razmkhah $M$, Jaberipour $M$, Hosseini $A$, Safaei $A$, Khalatbari B, Ghaderi A (2010) Expression profile of IL-8 and growth factors in breast cancer cells and adipose-derived stem cells (ASCs) isolated from breast carcinoma. Cellular Immunology, 265(1): 80-85.

18. Wang Y, Xu C, Du L, Cao J, Liu J, Su X, et al. (2013) Evaluation of the comet assay for assessing the dose-response relationship of DNA damage induced by ionizing radiation. International Journal of Molecular Sciences, 14(11): 2244922461.

19. Venkatesh P, Panyutin IV, Remeeva E, Neumann RD, Panyutin IG (2016) Effect of chromatin structure on the ex- tent and distribution of DNA double strand breaks produced by ionizing radiation; comparative study of hESC and differentiated cells lines. Int J Mol Sci, 17(1): 58.

20. Wu PK, Wang JY, Chen CF, Chao KY, Chang MC, Chen WM, et al. (2017) Early Passage Mesenchymal Stem Cells Display Decreased Radiosensitivity and Increased DNA Repair Activity. Stem Cells Translational Medicine, 6(6): 15041514.

21. Cmielova J, Havelek R, Soukup T, Jiroutová A, Visek B, Suchánek J, et al. (2012) Gamma radiation induces senescence in human adult mesenchymal stem cells from bone marrow and periodontal ligaments. Int J Radiat Biol, 88(5): 393-404.

22. Fekete N, Erle A, Amann EM, Furst D, Rojewski MT, Langonne $A$, et al. (2015) Effect of high-dose irradiation on human bone-marrow-derived mesenchymal stromal cells. Tissue Eng Part C Methods, 21(2): 112-22.

23. Ropolo M, Daga A, Griffero F, Foresta M, Casartelli G, Zunino A, et al. (2009) Comparative analysis of DNA repair in stem and nonstem glioma cell cultures. Molecular Cancer Research, 7(3): 383-392.

24. Jin $Y b$, Zhang $G y$, Lin $K R$, Chen $X p$, Cui JH, Wang $Y j$, et al. (2017) Changes of plasma cytokines and chemokines expression level in nasopharyngeal carcinoma patients after treatment with definitive intensity-modulated radiotherapy (IMRT). PloS one, 12(2): e0172264.

25. Bravatà V, Minafra L, Forte GI, Cammarata FP, Russo G, Di Maggio FM, et al. (2017) Cytokine profile of breast cell lines after different radiation doses. Int J Radiat Biol, 93 (11): 1217-1226.

26. Ponomaryov T, Peled A, Petit I, Taichman RS, Habler L, Sandbank J, et al. (2000) Induction of the chemokine stromal-derived factor-1 following DNA damage improves human stem cell function. The Journal of clinical investigation, 106(11): 1331-1339.

27. Bastianutto C, Mian A, Symes J, Mocanu J, Alajez N, Sleep $\mathrm{G}$, et al. (2007) Local radiotherapy induces homing of hematopoietic stem cells to the irradiated bone marrow.Cancer Research, 67(21): 10112-10116.

28. Tseng D, Vasquez-Medrano D, Brown J (2011) Targeting SDF-1/CXCR4 to inhibit tumour vasculature for treatment of glioblastomas. British Journal of Cancer, 104(12): 1805.

29. Nam H, Kim GH, Bae YK, Jeong DE, Joo KM, Lee K, et al. (2017) Angiogenic Capacity of Dental Pulp Stem Cell Regulated by SDF-1 $\alpha$-CXCR4 Axis. Stem Cells International, 2017: 8085462.

30. Galindo LT, Filippo TR, Semedo P, Ariza CB, Moreira CM, Camara NO, et al. (2011) Mesenchymal stem cell therapy modulates the inflammatory response in experimental traumatic brain injury. Neurology Research International, 2011: 564089.

31. Kang YJ, Yang SJ, Park G, Cho B, Min CK, Kim TY, et al. (2007) A Novel Function of Interleukin-10 Promoting SelfRenewal of Hematopoietic Stem Cells. Stem Cells, 25(7): 1814-1822.

Int. J. Radiat. Res., Vol. 19 No. 1, January 2021 